\title{
Grip Strength as a Cardiometabolic Marker
}

\author{
Jungun Lee* \\ Department of Family Medicine, Wonkwang University Sanbon Hospital, Wonkwang University School of Medicine, Gunpo, Korea
}

\section{See original paper on 291}

Muscle weakness is a key component of sarcopenia and frailty in older adults ${ }^{1,2)}$ and is used as an indicator of malnutrition. ${ }^{3)}$ Grip strength measurements using a handgrip dynamometer are recommended for the assessment of muscle weakness as the method is easy, quick, noninvasive, and reliable for measuring the maximum voluntary force of the hand. It is relatively inexpensive and can be used in both clinical and community settings. ${ }^{4)}$ Grip strength can provide information regarding an individual's nutritional status, muscle mass, physical function, and health status. ${ }^{5,6)}$

Several studies conducted on the Korean population have evaluated muscle strength using grip strength measurement in the Korean Journal of Family Medicine. ${ }^{7-12)}$ Most studies used national databases such as the Korea Health and Nutrition Examination Survey (KNHANES) ${ }^{7,8)}$ or the Korean Longitudinal Study of Aging. ${ }^{10-12)}$

However, there is no established standard protocol for measuring and reporting grip strength data. ${ }^{13)}$ Some studies used the absolute or dominant grip strengths, which were defined as the sum of the largest readings for both hands, and the grip strength of the dominant hand, respectively, whereas other studies used the mean grip strength of both hands. Relative grip strength is defined as the absolute grip strength divided by body mass index (BMI). Recently, BMI adjusted for muscle strength is used as a muscle quality index. For instance, the Foundation for the National Institutes of Health Sarcopenia Project has proposed a new approach for sarcopenia diagnosis wherein muscle weakness is adjusted for BMI instead of body weight or height. ${ }^{14)}$ Cardiometabolic risk had a stronger association with relative grip strength than with absolute grip strength. ${ }^{15)}$ However, Ho et al., ${ }^{16)}$ revealed that both the abso- lute and relative grip strengths had similar predictive abilities for cardiovascular disease and all-cause mortality. ${ }^{16)}$

Using the KNHANES 2015-2016, Chong et al. ${ }^{17)}$ assessed the association between the absolute and relative grip strengths and cardiometabolic outcomes in a Korean adult population stratified by sex and age. Grip strength measurements could be affected by the protocol used. After multiple measurements, the grip strength could reduce, and the maximum grip strength may be greater than the mean value of three trials. Therefore, Chong et al. ${ }^{17)}$ used the Southampton protocol to measure handgrip strength (HGS) following the suggestion of Roberts et al. ${ }^{13)}$ Chong et al. ${ }^{17)}$ revealed that grip strength has a negative relationship with $\mathrm{BMI}$, high-sensitivity C-reactive protein (hsCRP), and diabetes, and a positive relationship with physical activity in youths of both sexes. However, there were no significant association between dominant grip strength and BMI, relative grip strength and hsCRP, or relative grip strength and diabetes in elderly persons of both sexes. Compared to the absolute HGS, the relative HGS did not show a stronger association with hsCRP, blood pressure, BMI, and physical activity duration. However, the relative HGS showed a positive association with high-density lipoproteins in men aged 20-64 years. Our study suggests that grip strength may be a reliable index to screen for cardiometabolic disease.

Recently, normative reference values for grip strength across the lifespan in a Korean population aged 10-80 years have been published based on KNHANES 2014-2015. ${ }^{18)}$ Agerelated declines in grip strength were shown to begin as early as in the fifth decade of life. The life course trajectory identified for muscle weakness and any cutoff values related to relevant health outcomes were paramount.

Thus, grip strength could be used as a biomarker of healthy aging for people of all ages and may be an effective screening 
tool for cardiometabolic disease.

\section{CONFLICT OF INTEREST}

No potential conflict of interest relevant to this article was reported.

\section{ORCID}

Jungun Lee: https://orcid.org/0000-0001-8580-1445

\section{REFERENCES}

1. Won CW. Diagnosis and management of frailty in primary health care. Korean J Fam Med 2020;41:207-13.

2. Cruz-Jentoft AJ, Baeyens JP, Bauer JM, Boirie Y, Cederholm T, Landi F, et al. Sarcopenia: European consensus on definition and diagnosis: report of the European Working Group on Sarcopenia in Older People. Age Ageing 2010;39:412-23.

3. Martinez Olmos MA, Martinez Vazquez MJ, Martinez-Puga Lopez E, del Campo Perez V; Collaborative Group for the Study of Hospital Malnutrition in Galicia (Spain). Nutritional status study of inpatients in hospitals of Galicia. Eur J Clin Nutr 2005;59:938-46.

4. Bohannon RW. Muscle strength: clinical and prognostic value of hand-grip dynamometry. Curr Opin Clin Nutr Metab Care 2015;18: 465-70.

5. Collins J, Porter J, Truby H, Huggins CE. How does nutritional state change during a subacute admission?: findings and implications for practice. Eur J Clin Nutr 2016;70:607-12.

6. Taekema DG, Gussekloo J, Maier AB, Westendorp RG, de Craen AJ. Handgrip strength as a predictor of functional, psychological and social health: a prospective population-based study among the oldest old. Age Ageing 2010;39:331-7.

7. Kim BM, Yi YH, Kim YJ, Lee SY, Lee JG, Cho YH, et al. Association between relative handgrip strength and dyslipidemia in Korean adults: findings of the 2014-2015 Korea National Health and Nutrition Examination Survey. Korean J Fam Med 2020 Feb 12 [Epub]. https://doi. org/10.4082/kjfm.19.0073.

8. Lee SY, Son DH, Lee YJ. Relationship between sedentary time and handgrip strength in healthy Korean women: Korea National Health and Nutrition Examination Survey 2014-2016. Korean J Fam Med 2020 Jan 6 [Epub]. https://doi.org/10.4082/kjfm.19.0062.

9. Kang JY, Kim CH, Sung EJ, Shin HC, Shin WJ, Jung KH. The association between frailty and cognition in elderly women. Korean J Fam Med 2016;37:164-70.

10. Bae KH, Jo YH, Lee DR, Lee J. Trajectories of handgrip strength and their associations with mortality among older adults in Korea: analysis of the Korean Longitudinal Study of Aging. Korean J Fam Med 2020 May 27 [Epub]. https://doi.org/10.4082/kjfm.19.0140.

11. Jang SK, Kim JH. Association between hand grip strength and self-rated health in middle- and old-aged Korean citizens. Korean J Fam Med 2020;41:53-60.

12. Kim KH, Park SK, Lee DR, Lee J. The relationship between handgrip strength and cognitive function in elderly Koreans over 8 years: a prospective population-based study using Korean Longitudinal Study of Ageing. Korean J Fam Med 2019;40:9-15.

13. Roberts HC, Denison HJ, Martin HJ, Patel HP, Syddall H, Cooper C, et al. A review of the measurement of grip strength in clinical and epidemiological studies: towards a standardised approach. Age Ageing 2011;40:423-9.

14. Studenski SA, Peters KW, Alley DE, Cawthon PM, McLean RR, Harris $\mathrm{TB}$, et al. The FNIH sarcopenia project: rationale, study description, conference recommendations, and final estimates. J Gerontol A Biol Sci Med Sci 2014;69:547-58.

15. Lee WJ, Peng LN, Chiou ST, Chen LK. Relative handgrip strength is a simple indicator of cardiometabolic risk among middle-aged and older people: a nationwide population-based study in Taiwan. PLoS One 2016;11:e0160876.

16. Ho FK, Celis-Morales CA, Petermann-Rocha F, Sillars A, Welsh P, Welsh $\mathrm{C}$, et al. The association of grip strength with health outcomes does not differ if grip strength is used in absolute or relative terms: a prospective cohort study. Age Ageing 2019;48:684-91.

17. Chong H, Choi YE, Kong JY, Park JH, Yoo HJ, Byeon JH, et al. Association of hand grip strength and cardiometabolic markers in Korean adult population: the Korea National Health and Nutrition Examination Survey 2015-2016. Korean J Fam Med 2020;41:291-8.

18. Kim M, Won CW, Kim M. Muscular grip strength normative values for a Korean population from the Korea National Health and Nutrition Examination Survey, 2014-2015. PLoS One 2018;13:e0201275. 